\title{
Recognition of 16-18-Year-Old Adolescents for Guiding Physical Activity Interventions: A Cross-Sectional Study
}

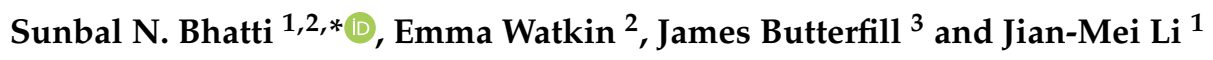 \\ 1 School of Biological Sciences, University of Reading, Reading RG6 6AS, UK; jian-mei.li@reading.ac.uk \\ 2 Faculty of Academic Studies, Farnborough College of Technology, Farnborough GU14 6SB, UK; \\ e.watkin@farn-ct.ac.uk \\ 3 Sports Coaching Department, North Kent College, Gravesend, Kent DA12 2JJ, UK; \\ jamesbutterfill@northkent.ac.uk \\ * Correspondence: s.n.bhatti@pgr.reading.ac.uk
}

Received: 18 June 2020; Accepted: 9 July 2020; Published: 11 July 2020

\begin{abstract}
Adolescence is a rapid life stage requiring special attention wherein personal autonomy is developed to govern independent lifestyles. Unhealthy lifestyles are integral to prevailing adolescent physical inactivity patterns. Understudied 16-18-year-olds were investigated to establish physical activity prevalences and influencing health-related lifestyle factors. Adolescents were recruited randomly across 2017-2019 from Farnborough College of Technology and North Kent College, UK. Demographic and health-related lifestyle information were gathered anonymously and analysed using SAS ${ }^{\circledR} 9.4$ software. Among the 414 adolescents included (48.3\% male and 51.7\% female), the mean (standard deviation (SD)) age was 16.9 (0.77). Approximately 15.2\% smoked and $20.8 \%$ were overweight/obese. There were $54.8 \%$ perceiving themselves unfit and $33.3 \%$ spent $>4 \mathrm{~h} /$ day on leisure-time screen-based activity. Around $80.4 \%$ failed to meet the recommended fruit/vegetable daily intake and $90.1 \%$ failed to satisfy UK National Physical Activity Guidelines, particularly females $(p=0.0202)$. Physical activity levels were significantly associated with gender, body mass index, smoking status, leisure sedentary screen-time, fruit/vegetable consumption and fitness perceptions. Those who were female, overweight/obese, non-smoking, having poor fitness perceptions, consuming low fruit/vegetables and engaging in excess screen-based sedentariness were the groups with lowest physical activity levels. Steering physical activity-oriented health interventions toward these at-risk groups in colleges may reduce the UK's burden of adolescent obesity.
\end{abstract}

Keywords: adolescence; health; obesity; physical activity; sedentariness; cardiovascular disease risk

\section{Introduction}

Adolescence is a fast-paced yet crucial life stage which bridges the transition between the dependencies in childhood to the independencies in adulthood wherein behaviours are effortlessly influenced. Cultivation of an unhealthy lifestyle during this period presents a major global health challenge in part owing to the cementing of such behaviours into adulthood [1]. As a consequence, chronic health-deteriorating behaviours manifest as obesity and cardiovascular complications which comprises the leading cause of mortality worldwide (ischaemic heart disease), thereby restricting longevity [2]. Insufficient physical activity, sedentariness and a poor diet are principle mediators of an obesogenic lifestyle [3]. Accordingly, the UK government has defined the National Physical Activity Guidelines (NPAG) for 5-18-year-olds, which advocate at least $60 \mathrm{~min}$ of physical activity per day (7 h/week), for an optimal health advantage [4]. However, comprehensive studies report that the NPAGs were largely unmet among those aged 11-15 years old [5] and $\sim 3$ million of $\geq 18$-year-olds in 
the UK [6]. The World Health Organization (WHO) defines adolescence as individuals of the ages $10-19$ years. In the realm of physical activity research in the UK, a crucial age (16-18 years) within adolescence is consistently omitted. This research gap has also been acknowledged by the National Centre for Sport and Exercise Medicine in an important report of physical activity prevalences and statistics, used extensively across the nation by policy makers, commissioners and practitioners [7]. Since the development of intellect, skills and changes in lifestyle behaviours are initiated across all ages of adolescence [8], bridging this gap is pivotal to support the targeting of initiatives for health behaviour change.

On account of the adoption of Westernised lifestyles, mounting rates of adolescent obesity have manifested in the current era, exhibiting patterns of incline since 1993 [9], bringing to the surface a crucial public health enigma. Among the regions, the southeast is the most populous in the UK [10], wherein almost a third of those aged $\geq 16$ are obese [11]. Importantly, its prevalence in British youth aged 10-24 years was the highest when compared with 14 European comparator countries [12]. It is widely recognised that failure to achieve NPAG is a principle contributor to the obesity epidemic in the 21st century [13].

Adolescents aged 16-18 experience a diversity of constraints lifted after school age, from parental restrictions to those within the schooling system. As they embark upon college, apprenticeships/traineeships, and/or work, the exposures and influences concurrently change wherein the strict school regulations are lifted. In the development of their personal autonomy, microenvironment influences and their heightened self-consciousness play a pivotal role in pursuing certain health behaviours, for instance, freedom to purchase a range of inexpensive, fat-rich foods suited to personal taste, or effortless attraction to interactive mobile/computer activities without limits (i.e., social media), which encourages excessive sedentary screen-based activity. Moreover, with the increasing expectations of post-school lives, multiple pressures are experienced (including social pressures, work-load and financial) which may reorient their behaviours and advocate injurious and lasting physically inactive lifestyles [1]. Indeed, transitionary life stages are described as obstacles to physical activity [14], which coincide with other adverse health behaviours. As we have previously reported, this holds true in large environments, such as educational institutions [15], as it exposes youth to targeted advertising and various societal influences. For UK adolescents between 16 and 18 years, it is mandatory to engage in some form of education in these settings. Furthermore, students in the southeast of England are prone to adopting unhealthy lifestyles compared to other regions [16]. Collectively, it is plausible that adverse health-related behaviours in adolescents in this region influence their physical activity levels. Since overwhelming evidence exists for the health benefits of physical activity [17], the investigation of health behaviour interaction with physical activity in 16-18-year-olds is of significant value.

Despite the initiative of governmental bodies to invest in this physical inactivity dilemma [18], minimal information describes the (1) physical activity levels and (2) demographic and health-related lifestyle factors that influence levels of physical activity of UK adolescents of 16-18 years. We hypothesise that, coinciding with insufficient physical activity levels, certain demographics and health-related behaviours are influential in the levels of physical activity in 16-18-year-old adolescents in the UK. The aims were to establish physical activity prevalences using NPAG achievement across genders and the health-related lifestyle factors influencing physical activity levels. Herein, we shed novel insight regarding potentially high-risk adolescents, which contributes to the establishment of prevalences in this understudied population. Moreover, the inferences may assist policy makers in steering health interventions to targeted groups to lower cardiovascular disease risk for thousands of UK adolescents. 


\section{Methods}

\subsection{Study Design}

The study was provided with ethical approval by the Faculty Ethics Sub-Committee of University Centre Farnborough, UK, according to their institutional procedures. Study information, including consent forms, were provided to participants prior to the dissemination of surveys. The anonymous multiple-choice design of the questionnaires permitted collection of self-filled data of each participant, including demographic data comprising gender, age, anthropometrics, ethnicity, medical conditions and home country of residence. Further, health-related lifestyle behaviours were collected which comprised: (1) quantity and frequency of cigarette smoking (cigarettes/week) categorised into smokers and non-smokers and, of those who were $\geq 18$ years old, quantity and frequency alcohol consumption (units/week) which was calculated using the formula: strength (alcohol by volume measured as a percentage of alcohol) $\mathrm{x}$ volume $(\mathrm{ml}) \div 1000=$ units of alcohol; (2) the duration spent in physical activity (h/week) which were ordered in to the categories: $0.25-2.5,2.5-8$ or $>8 \mathrm{~h} /$ week in compliance with NPAG [4]; (3) meal frequency (meals/day) and fruit/vegetable portions consumed (portions/day); (4) sleep duration (h/day) which was separated into $<7$ and $\geq 7 \mathrm{~h} /$ day in agreement with the recommended hours for young adults [19]; (5) leisure-time sedentariness on screen-based activities including computer use, watching television (TV) and gaming ( $\leq 4$ and $>4 \mathrm{~h} /$ day) and; (6) fitness self-perceptions (fit or unfit) and barriers to physical activity (open-ended). The body mass index (BMI) was categorised in keeping with the guidelines defined by the National Institutes of Health [20] as follows: underweight (BMI $<18.5 \mathrm{~kg} / \mathrm{m}^{2}$ ); normal weight, (BMI 18.5-24.9 kg/m²) and overweight/obese (BMI $\geq 25 / \geq 30 \mathrm{~kg} / \mathrm{m}^{2}$ ).

\subsection{Participant Recruitment and Data Collection}

Recruitment of volunteers took place during the years of 2018 and 2019 at both North Kent College, covering regions of Dartford, Gravesend and Kent (UK), and Farnborough College of Technology spanning regions of Surrey, Aldershot and Farnborough (UK). Recruitment was achieved by multi-stage probabilistic sampling using the 4000-student college census as a sampling frame and sampling randomly within departmental strata and then randomly sampling within classes, as our study intended to obtain a representative sample of UK college students for the southeast region of England. The inclusion criteria were students aged 16-18 years, within two years of college life and without documented medical conditions. Exclusion criteria were having a disability or documented medical condition which would otherwise limit the engagement in physical activity (i.e., bone/joint disorders), being above the age of 18 and being incomplete survey entries. Data were entered electronically for statistical analysis. This study was given favourable ethical opinion by the Faculty Ethics Sub-Committee of University Centre Farnborough (11-05-18), UK.

\subsection{Statistical Analysis}

Statistical analysis was performed using SAS software, Version 9.4 (SAS Institute Inc., Cary, NC, USA). Anthropometric and lifestyle data are reported as mean (standard deviation (SD)). A multinomial logistic regression was performed examining the associations between the response variable physical activity (0, 0.25-2.5, 2.5-8 and $>8 \mathrm{~h} /$ week) with gender, ethnicity, BMI, smoking status, alcohol consumption, eating frequency, fruit/vegetable intake, sleep duration, leisure screen-time (computer/TV) and perception of fitness. $p$-values and adjusted odds ratios (OR) were examined to explore parameter influence on physical activity levels. Statistical significance was accepted at $5 \%$ using a Wald chi-square test [21]. The use of a binomial logistic regression with dichotomised physical activity levels according to age-specific NPAG [4] was also performed. The results were presented with adjusted OR followed by their $95 \%$ confidence intervals for each explanatory variable, in brackets. 


\section{Results}

\subsection{Participant Demographics and Health-Related Lifestyle Behaviours}

Among the 414 participants, 200 (48.3\%) were males and 214 (51.7\%) were females with a mean (SD) age of 16.9 (0.77). Table 1 provides participant demographic information and health-related lifestyle behaviours. The majority $(n=401,96.9 \%)$ of participants were European residents and only $13(3.1 \%)$ were from other regions. There were 302 students $(72.9 \%)$ of a Caucasian ethnicity, $47(11.4 \%)$ were Asian, 17 (4.1\%) were Black African and the rest (48, 11.6\%) were from other ethnic origins. There were $63(15.2 \%)$ participants who reported to be smokers with a mean (SD) of 5.1 (19.22) cigarettes consumed/week.

The average BMI was $22.6(4.18) \mathrm{kg} / \mathrm{m}^{2}$, a value residing within the normal BMI range (Table 1). Among participants, 86 (20.8\%) were overweight/obese, 47 (11.4\%) were underweight, and $281(67.9 \%)$ were of a normal weight. More males were overweight $(48,24.0 \%)$ than females $(38,17.8 \%)$. Of the 108 participants who were 18 years old, 71 (65.7\%) reported alcohol consumption with an average (SD) intake of 5.9 (11.85) units/week for males and 5.4 (9.24) units/week for females, remaining below alcohol recommendations of 14 units/week [22]. A greater percentage of 18-year-old females (74.1\%) consumed alcohol relative to males (57.4\%).

Table 1. Demographics and health-related lifestyle behaviours by gender.

\begin{tabular}{|c|c|c|c|c|}
\hline Variable & Males $(n=200)$ & Females $(n=214)$ & Total $(n=414)$ & $p$-Value ${ }^{\text {a }}$ \\
\hline Age (years) mean (SD) & $16.9(0.78)$ & $16.9(0.76)$ & $16.9(0.77)$ & \\
\hline Residential status & $n(\%)$ & $n(\%)$ & $n(\%)$ & \\
\hline Europe & $189(94.5)$ & $212(99.1)$ & $401(96.9)$ & \\
\hline Outside Europe & $11(5.5)$ & $2(0.9)$ & $13(3.1)$ & 0.9844 \\
\hline \multicolumn{5}{|l|}{ Ethnicity } \\
\hline Caucasian & $140(70.0)$ & $162(75.7)$ & $302(72.9)$ & \\
\hline Asian & $29(14.5)$ & $18(8.4)$ & $47(11.4)$ & \\
\hline Black African & $8(4.0)$ & $9(4.2)$ & $17(4.1)$ & \\
\hline Other Ethnic Group & $23(11.5)$ & $25(11.7)$ & 48 (11.6) & 0.2445 \\
\hline BMI $\left(\mathrm{kg} / \mathrm{m}^{2}\right)$ mean (SD) & $23.2(4.34)$ & $22.0(3.96)$ & $22.6(4.18)$ & \\
\hline Underweight $(<18.5)$ & $22(11.0)$ & $25(11.7)$ & 47 (11.4) & \\
\hline Normal (18.5-24.9) & $130(65.0)$ & $151(70.6)$ & $281(67.9)$ & \\
\hline Overweight/Obese ( $\geq 25 / \geq 30 \mathrm{~kg})$ & $48(24.0)$ & $38(17.8)$ & $86(20.8)$ & 0.0038 \\
\hline Smoking (cigarette/week) mean (SD) & $5.2(18.31)$ & $5.0(20.08)$ & $5.1(19.22)$ & \\
\hline Non-smoker $(\%)$ & 85.0 & 84.6 & 84.8 & \\
\hline Smoker $(\%)$ & 15.0 & 15.4 & 15.2 & 0.0413 \\
\hline Alcohol (units/week) ${ }^{b}$ mean (SD) & $5.9(11.85)$ & $5.4(9.24)$ & $5.6(10.58)$ & \\
\hline No alcohol (\%) & 42.6 & 25.9 & 34.3 & \\
\hline Alcohol $(\%)$ & 57.4 & 74.1 & 65.7 & 0.8410 \\
\hline \multicolumn{5}{|l|}{ Eating frequency (meals/day) } \\
\hline$<3<$ & $64(32.0)$ & 109 (50.9) & $173(41.8)$ & \\
\hline$\geq 3$ & $136(68.0)$ & $105(49.1)$ & $241(58.2)$ & 0.4093 \\
\hline \multicolumn{5}{|l|}{ Sleeping (h/day) } \\
\hline$<7$ & $106(53.0)$ & $120(56.1)$ & $226(54.6)$ & \\
\hline$\geq 7$ & $94(47.0)$ & $94(43.9)$ & $188(45.4)$ & 0.8397 \\
\hline \multicolumn{5}{|l|}{ Leisure screen-time (h/day) } \\
\hline$\leq 4$ & $122(61.0)$ & $154(72.0)$ & $276(66.7)$ & \\
\hline$>4$ & $78(39.0)$ & $60(28.0)$ & $138(33.3)$ & 0.0065 \\
\hline \multicolumn{5}{|l|}{ Meeting NPAG (h/week) ${ }^{c}$} \\
\hline Not meeting guidelines $(<7)$ & $173(86.5)$ & $200(93.5)$ & $373(90.1)$ & \\
\hline Meeting guidelines $(\geq 7)$ & $27(13.5)$ & $14(6.5)$ & $41(9.9)$ & 0.0202 \\
\hline
\end{tabular}

a $p$-value analysing the influence of physical activity levels with health-related lifestyle factors yielded from the generalised logistic regression. ${ }^{b}$ Of those who were 18 years old. BMI, body mass index; NPAG, National Physical Activity Guidelines; SD, standard deviation. ${ }^{\mathrm{c}} p$-value as output from the binomial logistic regression analysis.

\subsection{Physical Activity Levels and Influencing Factors}

On average, time spent in physical activity was $3.2(2.70) \mathrm{h} /$ week for males and 2.3 (2.62) h/week for females, substantially lower than the NPAG (7 h/week) [4]. There were 373 (90.1\%) participants who failed to meet their age-specific NPAG (Table 1 and Figure 1a). Further, among the total participants, $121(29.2 \%)$ reported failure to engage in any form of physical activity ( $0 \mathrm{~h} /$ week $)$, in which a greater 
percentage were females $(73,34.1 \%)$ in comparison to males $(48,24.0 \%)$. Statistical analysis revealed that there were significantly more females $(200 / 214,93.5 \%)$ than males $(173 / 200,86.5 \%)$ who were not satisfying NPAG, $p$-value 0.0202 , OR $0.45(0.228,0.883)$ (Table 1$)$.

a.

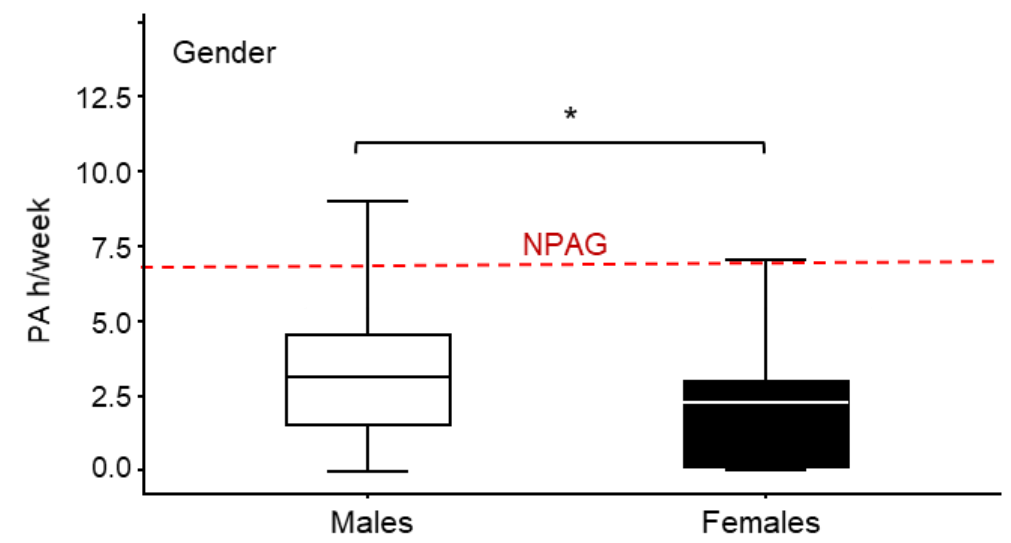

b.
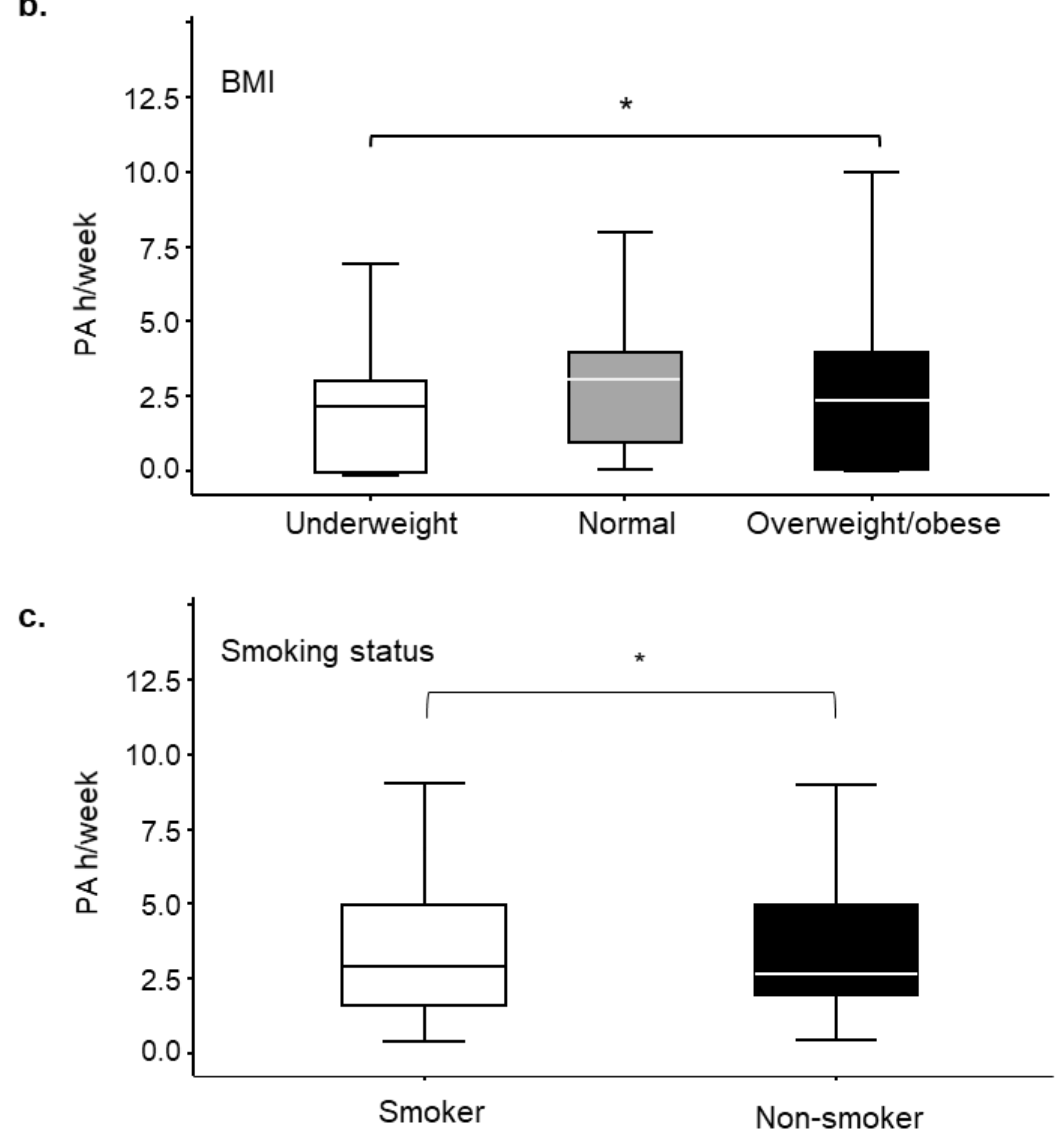

Figure 1. The relationship between the levels of physical activity and gender, body mass index (BMI) or smoking status in 16-18-year-old adolescents $(n=414)$. (a) Differences of physical activity levels between males [mean (standard deviation (SD)): $3.23(2.70), n=200$ ] and females [mean (SD): 2.27 (2.62), $n=214]$; (b) Differences of physical activity levels between BMI categories [mean (SD): underweight 2.18 (2.60), normal 3.00 (2.95), overweight/obese 2.30 (2.42)]; and (c) Differences of physical activity levels between smokers [mean (SD): 2.8 (2.83)] and non-smokers [mean (SD): 2.6 (2.55)]. Red dashed line indicates the UK National Physical Activity Guidelines (NPAG) recommended for those between the ages of 5 to 18 years old. Gender * $p$-value 0.0216, odds ratio (OR) 0.61 (0.404, 0.930); BMI (normal and overweight/obese) * $p$-value 0.0038, OR 2.15 (0.951, 4.854); smoking * $p$-value 0.0413 , OR 1.82 $(1.025,3.247)$. 
Another factor associated with physical activity levels was BMI, $p$-value 0.0038 , OR 2.15 (0.951, 4.854). A BMI of $\geq 25 \mathrm{~kg} / \mathrm{m}^{2}$ was associated with significantly lower levels of physical activity (Figure $1 \mathrm{~b}$ ). An individual's smoking status also arose as an influencing factor for physical activity levels, $p$-value 0.0413 , OR $1.82(1.025,3.247)$, such that smokers engaged in greater levels of physical activity than non-smokers (Figure 1c).

We found that $42(10.1 \%)$ students failed to consume any portion of fruit/vegetables per day. The majority of students $(209,50.5 \%)$ consumed 1-2 portions of fruit/vegetables per day, $82(19.8 \%)$ consumed 3-4 portions/day, and 81 (19.6\%) consumed $\geq 5$ portions/day with negligible gender differences (Figure 2a). Fruit/vegetable consumption was positively associated with physical activity (Figure $2 b), p$-value 0.0050 , OR $3.96(1.514,10.374)$. The mean (SD) value of physical activity for those consuming 1-2 portions/day was 2.3 (2.66) h/week, for those consuming 3-4 portions/day was 3.2 (2.60) $\mathrm{h} /$ week and for those consuming more than 5 portions/day was 3.3 (2.84) h/week. The lowest level of physical activity, 1.9 (2.39) h/week, was observed for those who did not have daily intake of fruits/vegetables. Further, we found that the majority of the participants $(241,58.2 \%)$ consumed $\geq 3$ meals/day, wherein the number for males $(136,68.0 \%)$ was greater than that for females $(105,49.1 \%)$ (Table 1). No association was observed between eating frequency and physical activity.

a.

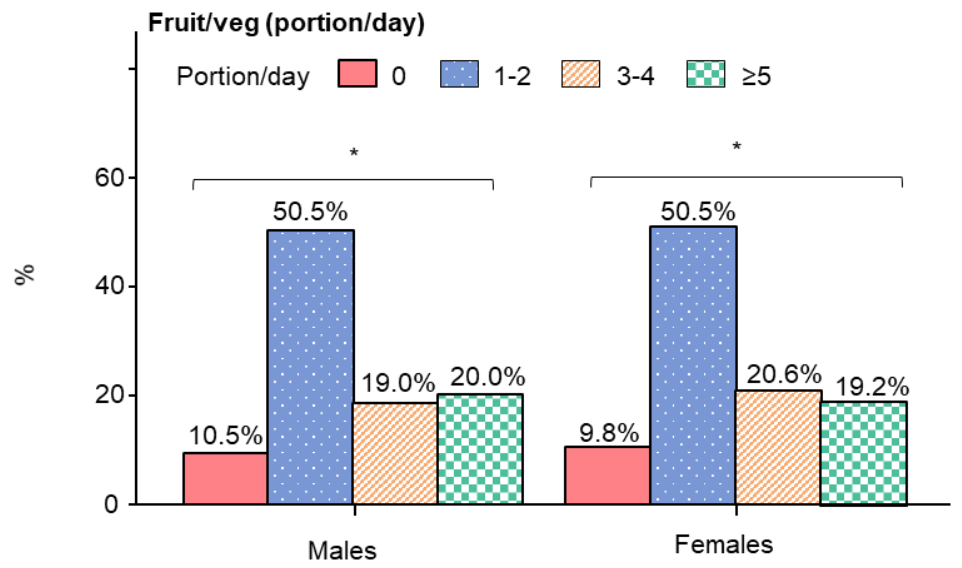

b.

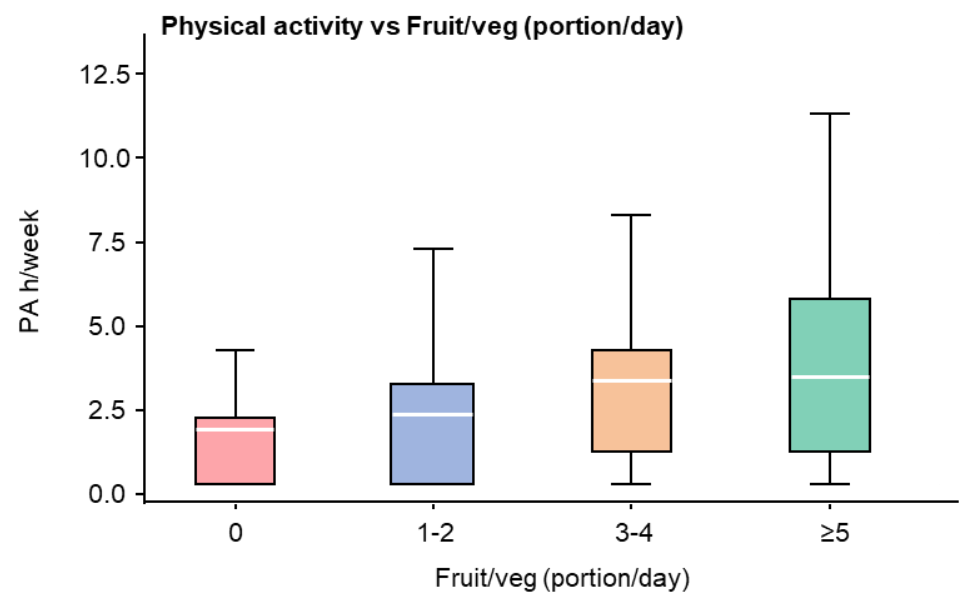

Figure 2. Daily average consumption of fruits and vegetables (portion/day) in participants and its relationship with the levels of physical activity. (a) Bar figure displaying the percentages of fruits and vegetables consumed daily by male and female students. (b) Relationship between the levels of physical activity and daily fruit and vegetables intake (portion/day). * $p$-value 0.0050, odds ratio OR $3.96(1.514,10.374)$. Data are represented as mean (standard deviation (SD)). 
There were 138 (33.3\%) students who spent $>4 \mathrm{~h} /$ day leisure-time sedentary in computing, gaming or watching movies with more males $(78,39.0 \%)$ than females $(60,28.0 \%)$. A small percentage of participants spent $>3 \mathrm{~h} /$ day on the computer $(78,18.8 \%)$ or watching television $(53,12.8 \%)$ which was a similar proportion across genders, except that nearly twice the number of males $(50,25.0 \%)$ spent $>3 \mathrm{~h} /$ day on the computer than females $(27,12.6 \%$ ) (Figure $3 \mathrm{a}, \mathrm{b})$. Leisure-time screen-based activity was associated with reduced levels of physical activity, $p$-value 0.0065 , OR $0.402(0.213,0.762)$.
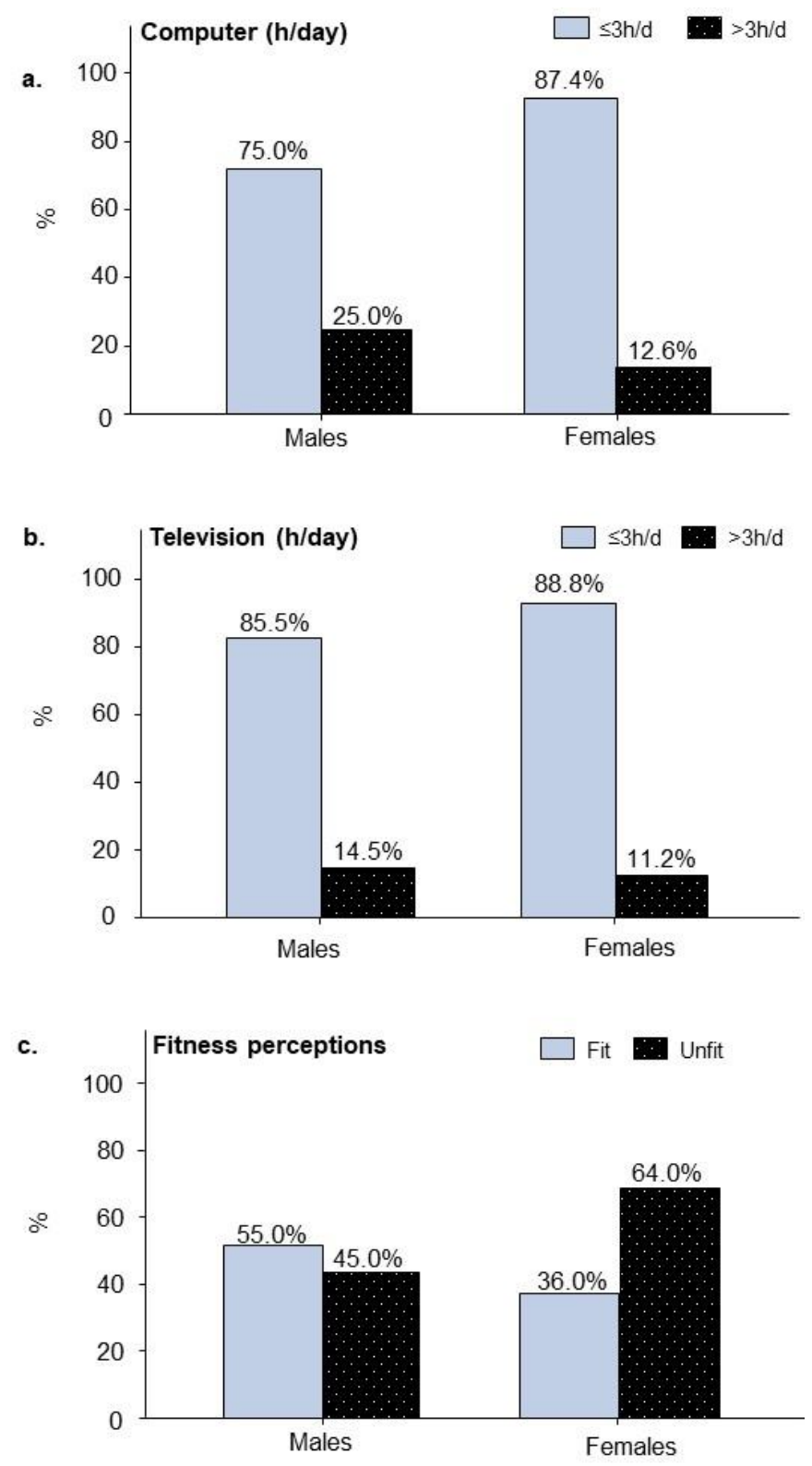

Figure 3. Differences in leisure-time sedentary screen behaviours and fitness perceptions between male $(n=200)$ and female adolescent students $(n=214)$. (a) Percentages of students engaged in leisure-time computer activity (h/day). (b) Percentages of students engaged in leisure-time television (TV) activity (h/day). (c) Percentages of students separated by self-assessed fitness perception. The influence of physical activity levels are given by the $p$-values and odds ratios (OR) that follow: sedentary behaviours including (a) computer (h/day), p-value 0.0067, OR $1.887(1.192,2.985)$ and (b) watching television, $p$-value 0.0052 , OR $0.402(0.213,0.762)$; (c) fitness perceptions, $p$-value $<0.0001$, OR $0.325(0.208,0.507)$. 
We also found that $226(54.6 \%)$ participants slept less than the recommendation ( $<7 \mathrm{~h} /$ day) [19]. It appeared that females $(120,56.1 \%)$ spent less time in sleep than males $(106,53.0 \%)$, though there was no correlation with physical activity.

\subsection{Perception of Fitness and Barriers to Physical Activity}

More than half of all participants $(227,54.8 \%)$ perceived themselves as being physically unfit, with more females $(137,64.0 \%)$ reporting this in comparison to males $(90,45.0 \%)$, (Figure 3c). Fitness perceptions were associated with physical activity, such that those who perceived themselves as unfit had a three-fold reduction in physical activity levels, $p$-value $<0.0001$, OR $0.325(0.208,0.507)$ (Figure 3c). There were 175 (42.3\%) participants who thought themselves unfit and also failed to meet NPAG, wherein $65(32.5 \%)$ were males and $110(51.4 \%)$ were females. Moreover, there were $89(21.5 \%)$ participants who perceived themselves to be fit yet failed to meet NPAG. The explanations given for not meeting NPAG were "No time" and "Don't want to" (91.1\%), followed by "No facility" (8.5\%) and "No money" (0.4\%).

\section{Discussion}

Adolescence is a rapid stage of life requiring special attention [8], wherein personal autonomy is developed for the governance of independent lifestyles. An estimated 738 thousand 16-18-year-old adolescents are required to be trained in UK colleges that provide work, apprenticeships and/or education in an influential environment instilling health-related behaviour modification [23]. Among these changes, insufficient physical activity damages health, persists into adulthood [1] and predicts cardiovascular disease risk [24]. Adopting NPAG improves diverse aspects of health such as cognitive function, disease and longevity $[1,2,17]$. Health research pertaining to adolescents is heavily focused on school or university ages [25-28]. Minimal studies explore 16-18-year-olds, which is a key transitionary life stage important in reinforcing lifestyle trajectories, thereby deeming valuable the recognition of their physical activity levels and the behaviours influencing physical activity engagement.

Approaching 50\% of students within the southeast of England, a population-dense region, gain weight upon commencing higher education $[10,16]$. This population is gaining extensive interest by public health policy-makers worldwide for health-intervention, thereby making it particularly constructive to recognise those at risk [12]. A recent study has shown that university students who performed $<3 \mathrm{~h} /$ week physical activity (any form of exercise or sport) had significantly lower cardiorespiratory fitness $\left(\mathrm{VO}_{2} \mathrm{max}\right)$ and heart rate recovery, which put them at risk for cardiometabolic diseases [29]. Herein, we provide novel indication that the prevalence of college students failing to achieve NPAG $(90.1 \%)$ is of a greater degree than estimated, and to a larger degree for females. According to other reports, recently the lack of physical activity in 15-year-old adolescents reached $48 \%$ to around $65 \%$ in various regions of the world [30,31] and rose to around $80 \%$ in UK adolescents $[5,32]$. As we found that $60.8 \%$ of students were active yet failed to meet NPAG, we suggest that the intention for physical activity is prevalent, though they fail to reap the health benefit due to insufficient motivation and time. Commonly, females justify physical inactivity due to social pressures, forced competition, time constraints and body dissatisfaction [33]. Agreeing with the latter, we show that more females have poorer self-perceptions of fitness than males which correlated well with their inability to achieve NPAG. Collectively, physical activity educational interventions in college students may be beneficial, particularly for females, and may improve fitness self-perceptions.

Overweight/obesity is an established risk factor for cardiovascular diseases [3]. Herein, a large percentage of the cohort $(20.8 \%)$ were overweight/obese, particularly males, indicating that the prevalence of obesity may be worse in college students than general figures suggested for UK adolescents (8.1\%) [12]. Moreover, mirroring our finding, it is unanimously agreed that BMI is negatively correlated with physical activity in youth [34]. Previously, the consensus was that smoking in adolescence negatively correlated with physical activity [35], since then research has 
demonstrated that certain forms of physical activity (walking/cycling), when controlled for risk factors (peer influence/substance misuse), enhance the odds of smoking by four-fold [36]. Harmonising with this interaction, herein smokers were more likely to engage in greater levels physical activity than non-smokers. Explanations of this paradoxical interaction bring to surface that underlying motives (weight loss) and/or seeking membership thresholds promotes increased cigarette use [36]. Taken together, educational intervention of specific physical activities which exhibit a negative association with smoking (running/racquet sports) in college students may promote health.

Mounting sedentariness among youngsters poses a risk for the development of cardiometabolic diseases, particularly in obese adolescents [37]. There were $33.3 \%$ of participants in this cohort who reported excessive sedentariness which is negatively associated with physical activity levels. Promoting compensatory physical activity between lecture hours and encouraging leisure-time outdoor activity, at minimum engaging in longer durations of low-level activity, could make significant contributions to cardiovascular, neuromuscular, bone and mental health for adolescents [17,38,39].

The WHO recommends $\geq 5$ portions of fruit/vegetables per day as an important dietary component for chronic disease prevention [40], yet we found that the majority $(80.4 \%)$ of students failed to meet this standard. In agreement with our findings, reports suggest that engagement in physical activity motivates one to practice healthy eating [41]. Conversely, others suggest, through unconscious energy homeostasis, adopting a healthy behaviour in one area may endorse unhealthy behaviours in another area [42]. In view of the prevalence of low fruit/vegetable consumers in our cohort, providing college interventions to advocate the nutritional value of consuming fruit/vegetables and raising health-consciousness may positively influence their physical activity levels. Furthermore, the distribution of an individual's calorie intake throughout the day influences weight status and researchers suggest a protective effect of increased meal frequency on obesity in the young [43]. Our results, however, reveal more than half (58.2\%) of adolescent students consume $\geq 3$ meals/day, though no association existed between meal frequency and physical activity levels.

There were limitations of the study methodology as anthropometric and lifestyle behaviours were not objectively measured but obtained solely through self-report by participants, which may give rise to inaccuracies. For example, some adolescents may misestimate their weight or physical activity levels, which may affect the associations found herein. Nevertheless, the reliability of survey data was previously demonstrated as valid and reliable [44]. Another limitation is that the participants of this study were recruited from two colleges which may not be representative of the entire population of this age in the UK; however, the geographic distribution of individuals in this study managed to cover several populated suburb regions of southeast England. The ethnicity percentage in this sample closely reflects the characteristics of the general 16-18 student population reported by the Department for Education [45]. Furthermore, the cross-sectional nature of the study prohibits the inference of causality. Although they are prevalent behaviours, it is important to note that the engagement in screen-based activities (computer/TV) may not wholly represent time spent sedentary. However, given the limited information available for the prevalence of physical activity levels of 16-18-year olds in the UK, our study delivers statistics for this research gap and indicates important groups to target for health promotion.

\section{Conclusions}

In closing, the vast majority (90.1\%) of 16-18-year-old adolescents in the southeast of England fail to meet NPAG, and $80.4 \%$ fail to meet the recommended fruit/vegetable daily intake. We indicate that physical activity is diminished in adolescents who are females, overweight/obese, non-smokers, have poor fitness perceptions, low fruit/vegetable consumption and engage in high screen-based sedentariness. Steering certain forms of physical activity-oriented health interventions toward these at-risk groups in colleges may reduce the UK's prevailing enigma of adolescent obesity and future cardiovascular outcomes. 
Author Contributions: Conceptualization, S.N.B. and J.-M.L.; Methodology, S.N.B.; Data curation, S.N.B.; Resources, S.N.B., E.W. and J.B.; Formal analysis, S.N.B.; Investigation, S.N.B.; Project administration, S.N.B.; Visualization, S.N.B.; Supervision, J.-M.L.; Writing - Original Draft, S.N.B.; Writing - Review \& Editing, S.N.B. and J.-M.L. All authors have read and approved the final version of the manuscript, and have agreed with the order of presentation of the authors.

Funding: This research did not receive any specific grant from funding agencies in the public, commercial, or not-for-profit sectors.

Conflicts of Interest: The authors declare that they have no conflicts of interest.

Availability of data and materials: The datasets used and analysed during the current study are available from the corresponding author on reasonable request.

\section{References}

1. Hayes, G.; Dowd, K.P.; MacDonncha, C.; Donnelly, A.E. Tracking of Physical Activity and Sedentary Behavior from Adolescence to Young Adulthood: A Systematic Literature Review. J. Adolesc. Heal. 2019, 65, 446-454. [CrossRef] [PubMed]

2. del Pozo Cruz, B.; McGregor, D.E.; del Pozo Cruz, J.; Buman, M.P.; Palarea-Albaladejo, J.; Alfonso-Rosa, R.M.; Chastin, S.F.M. Integrating sleep, physical activity, and diet quality to estimate all-cause mortality risk: A combined compositional clustering and survival analysis of the NHANES 2005-2006 cycle. Am. J. Epidemiol. 2020. [CrossRef]

3. Obesity and Overweight. 2020. Available online: https://www.who.int/news-room/fact-sheets/detail/obesityand-overweight (accessed on 7 July 2020).

4. UK Chief Medical Officers' Physical Activity Guidelines 7 September 2019. Available online: https://assets.publishing.service.gov.uk/government/uploads/system/uploads/attachment_data/file/ 832868/uk-chief-medical-officers-physical-activity-guidelines.pdf (accessed on 7 July 2020).

5. Corder, K.; van Sluijs, E.M.; Goodyer, I.; Ridgway, C.L.; Steele, R.M.; Bamber, D.; Dunn, V.; Griffin, S.J.; Ekelund, U. Physical Activity Awareness of British Adolescents. Arch. Pediatr. Adolesc. Med. 2011, 165, 603-609. [CrossRef] [PubMed]

6. British Active Students Survey: 2017/2018 Report. Spring 2018. Available online: https://www.precor.com/ sites/default/files/BASS\%20report\%20FINAL.pdf (accessed on 7 July 2020).

7. National Centre for Sport and Exercise Medicine. Physical Activity for Children and Young People, Evidence Briefing February 2014. Available online: http://www.ncsem-em.org.uk/wp-content/uploads/2018/07/cyp_ evidence_briefing.pdf (accessed on 7 July 2020).

8. Adolescence: A Period Needing Special Attention-Recognizing-Adolescence 2014. Available online: https://apps.who.int/adolescent/second-decade/section2/page1/recognizing-adolescence.html (accessed on 7 July 2020).

9. Roth, G.A.; Huffman, M.D.; Moran, A.E.; Feigin, V.; Mensah, G.A.; Naghavi, M.; Murray, C.J.L. Global and regional patterns in cardiovascular mortality from 1990 to 2013. Circulation 2015, 132, 1667-1678. [CrossRef] [PubMed]

10. Population estimates-Office for National Statistics 24 June 2020. Available online: https://www.ons.gov.uk/ peoplepopulationandcommunity/populationandmigration/populationestimates (accessed on 7 July 2020).

11. Public Health England. Patterns and Trends in Adult Obesity: A Presentation of Data on Adult Obesity March 2019. Available online: https://app.box.com/s/og3q86aqejc99okxe9xyvpfvo21xai21/file/256370456621 (accessed on 7 July 2020).

12. Shah, R.; Hagell, A.; Cheung, R. International Comparisons of Health and Wellbeing in Adolescence and Early Adulthood February 2019. Available online: https://www.nuffieldtrust.org.uk/files/2019--02/1550657729_ntayph-adolescent-health-report-web.pdf (accessed on 7 July 2020).

13. Health Survey for England 2017 Adult and Child Overweight and Obesity 4 December 2018. Available online: http://healthsurvey.hscic.gov.uk/media/78619/HSE17-Adult-Child-BMI-rep.pdf (accessed on 7 July 2020).

14. Martins, J.; Marques, A.; Sarmento, H.; Carreiro Da Costa, F. Adolescents' perspectives on the barriers and facilitators of physical activity: A systematic review of qualitative studies. Health Educ. Res. 2015, 30, 742-755. [CrossRef] [PubMed]

15. Bhatti, S.N.; Leidi, A.; Leake, D.; Li, J.-M. Studying biological science does not lead to adoption of a healthy lifestyle. Perspect. Public Health 2019, 1757913919890889. [CrossRef] 
16. The Independent, Students in the South East of England Gain the Most Weight in Their First Year 15 September 2014. Available online: https:/www.independent.co.uk/life-style/health-and-families/ students-in-the-south-east-of-england-gain-the-most-weight-in-their-first-year-9734072.html (accessed on 7 July 2020).

17. Chaabene, H.; Lesinski, M.; Behm, D.G.; Granacher, U. Performance-and health-related benefits of youth resistance training. Sport. Orthop. Traumatol. 2020. [CrossRef]

18. Public Health England What Works in Schools and Colleges to Increase Physical Activity? March 2020. Available online: https:/assets.publishing.service.gov.uk/government/uploads/system/uploads/ attachment_data/file/876242/Guidance_to_increase_physical_activity_among_children_and_young_ people_in_schools_and_colleges.pdf (accessed on 7 July 2020).

19. Watson, N.F.; Badr, M.S.; Belenky, G.; Grandner, M.A.; Kushida, C.; Malhotra, R.K.; Martin, J.L. Recommended Amount of Sleep for a Healthy Adult: A Joint Consensus Statement of the American Academy of Sleep Medicine and Sleep Research Society. J. Clin. Sleep Med. 2015, 11, 591-592. [CrossRef]

20. Expert Panel on the Identification, Treatment of Overweight, Obesity in Adults (US); National Heart, Lung, Blood Institute; National Institute of Diabetes, Digestive, Kidney Diseases (US). Clinical guidelines on the identification, evaluation, and treatment of overweight and obesity in adults. The Evidence Report, NIH Publication No. 98-4083. Arch. Intern. Med. 1998. [CrossRef]

21. O'Connell, A. Logistic Regression Models for Ordinal Response Variables; Sage: Thousand Oaks, CA, USA, 2011. [CrossRef]

22. UK Chief Medical Officers' Alcohol Guidelines Review January 2016. Available online: https://assets.publishing.service.gov.uk/government/uploads/system/uploads/attachment_data/file/ 489795/summary.pdf (accessed on 7 July 2020).

23. Association of Colleges. College Key Facts 2019/2020. Available online: https://www.aoc.co.uk/files/aoccollege-key-facts-2019-20pdf (accessed on 7 July 2020).

24. Lear, S.A.; Hu, W.; Rangarajan, S.; Gasevic, D.; Leong, D.; Iqbal, R.; Casanova, A.; Swaminathan, S.; Anjana, R.M.; Kumar, R.; et al. The effect of physical activity on mortality and cardiovascular disease in 130000 people from 17 high-income, middle-income, and low-income countries: The PURE study. Lancet 2017, 390, 2643-2654. [CrossRef]

25. Aceijas, C.; Waldhäusl, S.; Lambert, N.; Cassar, S.; Bello-Corassa, R. Determinants of health-related lifestyles among university students. Perspect. Public Health 2017, 137, 227-236. [CrossRef]

26. Yahia, N.; Wang, D.; Rapley, M.; Dey, R. Assessment of weight status, dietary habits and beliefs, physical activity, and nutritional knowledge among university students. Perspect. Public Health 2016, 136, 231-244. [CrossRef] [PubMed]

27. Dumuid, D.; Olds, T.; Lewis, L.K.; Martin-Fernández, J.A.; Barreira, T.; Broyles, S.; Chaput, J.P.; Fogelholm, M.; Hu, G.; Kuriyan, R.; et al. The adiposity of children is associated with their lifestyle behaviours: A cluster analysis of school-aged children from 12 nations. Pediatr. Obes. 2018, 13, 111-119. [CrossRef]

28. Litsfeldt, S.; Ward, T.M.; Hagell, P.; Garmy, P. Association between Sleep Duration, Obesity, and School Failure Among Adolescents. J. Sch. Nurs. 2020. [CrossRef]

29. Fan, L.M.; Collins, A.; Geng, L.; Li, J.-M. Impact of unhealthy lifestyle on cardiorespiratory fitness and heart rate recovery of medical science students. BMC Public Health 2020, 20, 1-8. [CrossRef] [PubMed]

30. Baqal, O.J.; AlBuhairan, F. Urgent Need for Physical Activity Policies and Promotion Among Adolescents In Saudi Arabia: Lessons From "Jeeluna”. J. Adolesc. Heal. 2019, 64, S75. [CrossRef]

31. Hansen, B.H.; Kolle, E.; Steene-Johannessen, J.; Dalene, K.E.; Ekelund, U.; Anderssen, S.A. Monitoring population levels of physical activity and sedentary time in Norway across the lifespan. Scand. J. Med. Sci. Sport. 2019, 29, 105-112. [CrossRef]

32. Guthold, R.; Stevens, G.A.; Riley, L.M.; Bull, F.C. Global trends in insufficient physical activity among adolescents: A pooled analysis of 298 population-based surveys with 1.6 million participants. Lancet Child Adolesc. Heal. 2020, 4, 23-35. [CrossRef]

33. Corr, M.; McSharry, J.; Murtagh, E.M. Adolescent Girls' Perceptions of Physical Activity: A Systematic Review of Qualitative Studies. Am. J. Heal. Promot. 2019, 33, 806-819. [CrossRef] [PubMed]

34. Eddolls, W.T.B.; McNarry, M.A.; Lester, L.; Winn, C.O.N.; Stratton, G.; Mackintosh, K.A. The association between physical activity, fitness and body mass index on mental well-being and quality of life in adolescents. Qual. Life Res. 2018, 27, 2313-2320. [CrossRef] [PubMed] 
35. Wichstrøm, L.; von Soest, T.; Kvalem, I.L. Predictors of growth and decline in leisure time physical activity from adolescence to adulthood. Heal. Psychol. 2013, 32, 775. [CrossRef] [PubMed]

36. Audrain-McGovern, J.; Rodriguez, D. All physical activity may not be associated with a lower likelihood of adolescent smoking uptake. Addict. Behav. 2015, 51, 177-183. [CrossRef] [PubMed]

37. Vella, C.A.; Taylor, K.; Nelson, M.C. Associations of leisure screen time with cardiometabolic biomarkers in college-aged adults. J. Behav. Med. 2020, 1-12. [CrossRef]

38. Kandola, A.; Lewis, G.; Osborn, D.P.J.; Stubbs, B.; Hayes, J.F. Depressive symptoms and objectively measured physical activity and sedentary behaviour throughout adolescence: A prospective cohort study. Lancet Psychiatry 2020, 7, 262-271. [CrossRef]

39. Kumar, B.; Robinson, R.; Till, S. Physical activity and health in adolescence. Clin. Med. 2015, 15, 267. [CrossRef]

40. Healthy Diet 29 April 2020. Available online: https://www.who.int/news-room/fact-sheets/detail/healthy-diet (accessed on 7 July 2020).

41. Manz, K.; Mensink, G.B.M.; Finger, J.D.; Haftenberger, M.; Brettschneider, A.K.; Barbosa, C.L.; Krug, S.; Schienkiewitz, A. Associations between physical activity and food intake among children and adolescents: Results of KIGGS wave 2. Nutrients 2019, 11, 1060. [CrossRef]

42. Blundell, J.E.; Gibbons, C.; Caudwell, P.; Finlayson, G.; Hopkins, M. Appetite control and energy balance: Impact of exercise. Obes. Rev. 2015, 16, 67-76. [CrossRef]

43. Kelishadi, R.; Qorbani, M.; Motlagh, M.E.; Heshmat, R.; Ardalan, G.; Bahreynian, M. Association of eating frequency with anthropometric indices and blood pressure in children and adolescents: The CASPIAN-IV Study. J. Pediatr. 2016, 92, 156-167. [CrossRef]

44. Al-Hazzaa, H.M.; Abahussain, N.A.; Al-Sobayel, H.I.; Qahwaji, D.M.; Musaiger, A.O. Physical activity, sedentary behaviors and dietary habits among Saudi adolescents relative to age, gender and region. Int. J. Behav. Nutr. Phys. Act. 2011, 8, 140. [CrossRef]

45. Department for Education Further Education Participation 16 April 2019. Available online: https://www. ethnicity-facts-figures.service.gov.uk/education-skills-and-training/a-levels-apprenticeships-furthereducation/further-education-participation/latest\#by-ethnicity-compared-with-the-overall-population (accessed on 7 July 2020).

(C) 2020 by the authors. Licensee MDPI, Basel, Switzerland. This article is an open access article distributed under the terms and conditions of the Creative Commons Attribution (CC BY) license (http://creativecommons.org/licenses/by/4.0/). 